\section{Veterinary education on fostering food safety and governance achieving a healthy nation in Bangladesh}

\section{Mufizur Rahman, S.M. Lutful Kabir}

Department of Microbiology and Hygiene, Faculty of Veterinary Science, Bangladesh Agricultural University, Mymensingh, Bangladesh

\section{Abstract}

Since veterinary medicine plays an important role in assuring a nation's food safety, therefore the present status of our food safety, where large numbers of consumers in Bangladesh have become victims of consuming adulterated foods, needs to be enhanced and governed by the guideline of veterinary and public health educators. This article highlights the need of an integrated collaborative approach between academicians and government officials for the creation and dissemination of food-safety teaching driving force to mitigate food borne diseases, ensure food safety, control mischievous and fraudulent adulteration - all destined to a harmonious national health strategic action plan. Veterinary education is very effective for correct implementation of the stable to table concept and best serves the public when it is updated on current market needs of food products and measures protecting animal health. Universities in Europe and USA have adjusted their veterinary medicine curricula during the past few years. Experts predicted determinant changes by 2020 that would influence the work of the veterinarians. All of them are in favor of placing food quality and food safety and public health as the highest priorities in future veterinary education. In Bangladesh, Universities and Veterinary Colleges are producing qualified Veterinary Food Hygienists to deal with matters of health and demands for consumers' food protection. The veterinary education blends veterinarians with strong capacity to advocate the assurance of food quality and safety from farm to fork. Government in collaboration with veterinary food hygienist should advocate academic and field covered sciencebased food safety system. It is hoped that in the near future Bangladesh will come forward with veterinary public health responsibilities incorporated in national food safety program. The concerned authorities in collaboration with international public health authority like WHO should establish a center for food safety, food quality control, and zoonoses.

\section{Introduction}

In recent days due to indiscriminate adulteration and uncontrolled appearance of adulterated foods in markets and elsewhere, the public as well the government of Bangladesh is greatly concerned about food safety, and there is a growing realization that we are ill equipped to handle major food-borne illness outbreaks. The public has started to question the quality of foods, as they are appearing in increasing numbers in supermarkets and retail grocery stores. Food safety has now become an important topic as large numbers of consumers in Bangladesh have become victims of consuming adulterated foods. Some of the examples are presented below: i) Using of dead chicken meat by certain so called elegant restaurants; ii) Selling of sweets mixed with health hazardous substances; iii) Soaking of mangoes and other fruits in chemicals; iv.) using of chemicals to ripen bananas; v) adding formalin to fish and milk; vi) offering of local beef at exorbitant price with false tag in the name of California Beef or Texas Beef and recently anthrax infected meats are eaten that definitely pose high health hazard risk.

Since veterinary medicine plays an important role in assuring the safety of any nation's food supply, therefore the present status of our food safety needs to be enhanced and governed by the guideline of veterinary and public health educators with newly emerging resource for food-safety educational materials in tune with the Directives of the Government Officials empowered with the application and management of food safety and vested with power to wipe out the emerging and reemerging public health threat. This article highlights the imperative need of an integrated collaborative approach between academicians and Government officials for the creation and dissemination of food-safety teaching driving force to be applied to mitigate food borne diseases, ensure food safety, control mischievous and fraudulent adulteration - all destined to develop a harmonious nation health strategic action plan. The academicians of veterinary education of Bangladesh have been long experiencing and promoting designs to disseminate and develop materials for an integrative veterinary food safety management, but unfortunately due to failure of the government to recognize their competency, these veterinarians are not given opportunity or engaged to play key role in food safety and public health issues. It is however accepted by the WHO and public health related agencies all over the world that the public health veterinarians do possess the capacity to advise government, food industries, professional groups and build consumers' awareness on the effectiveness of food safety management and controls. In the
Correspondence: S.M. Lutful Kabir, Department of Microbiology and Hygiene, Faculty of Veterinary Science, Bangladesh Agricultural University, Mymensingh 2202, Bangladesh.

Tel. +880.91.67401-6 - Fax: +880.91 .61510$

E-mail: lkabir79@gmail.com

Key words: veterinary education, food safety, governance and healthy nation.

Acknowledgments: the authors wish to thank the colleagues of the Department of Microbiology and Hygiene, Faculty of Veterinary Science, Bangladesh will Agricultural University, Mymensingh-2202, Bangladesh for critically reading the manuscript and giving appreciation.

Contributions: the authors contributed equally.

Received for publication: 2 January 2013.

Revision received: 7 March 2013

Accepted for publication: 10 March 2013.

This work is licensed under a Creative Commons Attribution NonCommercial 3.0 License (CC BYNC 3.0).

(C) Copyright M.M. Rahman and S.M. Lutful Kabir, 2013 Licensee PAGEPress srl, Italy

Veterinary Science Development 2013; 3:e4

doi:10.4081/vsd.2013.e4

present paper concern has been expressed about the public health veterinarians profiling work force and activities needed to adequately address the scientific, technological, social, political and economic challenges facing global and regional food safety and public health.

\section{The significance of veterinary education with respect to food safety}

Ensuring people safe food has been the major task of veterinarians since the inception and development of the veterinary profession in the $18^{\text {th }}$ century. Today the veterinary profession is the only health profession that includes food safety as a significant part of instruction. ${ }^{1}$ Qualified veterinary food hygienists and public health veterinarians can play leading as well as professional roles in vitalizing and strengthening QC and QA programs of food safety and food hazards, in controlling zoonoses, incorporating plans for the social and economic development of the country and undertaking collaborative activities with multidisciplinary national and international agencies.

Veterinary medicine that concerns a wide range of animal species, encompasses a broad 
spectrum of multidisciplinary approach of scientific knowledge that continually changes through the practical use of research findings. Specific knowledge on the needs of this multidisciplinary approach has grown to such an extent that new specialty disciplines are now imperative to better serve veterinary medicine. This accumulation of veterinary knowledge is becoming huge and expanding. As shown in Figure 1, firstly it can be divided into three major fields, each field deals with specific professional specialties. One field, farm animals include additional specialty centered to food hygiene. Although each has an important role to play in issues of public health, the latter is most important. Farm animals are gifts of the nature. They are kept for their products, indispensable to the survival of all human races. Thus, there is no denying the fact and it is crystal clear that farm animal veterinarians and public health veterinarians, through their involvement in the production and distribution of wholesome foods of animal origin, can help to form public opinion on issues of safety and economic policy.

With respect to farm animals, animal health, and public health, veterinary education is the most effective and best serves the public when it is updated on current market needs of food products of animal origin, measures protecting animal health (herd health management, disease surveillance, and bio-security) and thereby contributing to protect human health. 2 The new trend among consumers, producers as well as among all parts of the food industry is to develop a safe system of food production centered on the concept from the stable to the table or from the farm to the fork. Consumers are now concerned with the appropriateness of veterinary management measures taken in different aspects of animal production (especially on farm procedures) and they are giving due attention to the animal's impact on public health and food protection. As a consequence public health now rests on an integral aspect of veterinary management service, which is disseminated through a prominent part of veterinary education. Likewise, the world community needs the help of veterinary professionals to produce sufficient amounts of safe food, to control and eradicate the increasingly frequent trans-boundary transmission of disease, and to improve the health of both man and animals, at a global level as well as locally. 3

In order to better protect consumers on issues of food safety, efforts are made to ensure the safety of all procedures involved in producing foods of animal origin so that there will be no health risk to humans from consuming such products. In this viewpoint the future livestock veterinarians need to be familiar, through proper education, with veterinary management programs meeting the required standards of the stable to table concept in order to meet the consumer health demands. ${ }^{4}$ This concept rightfully gives the distinct responsibility of public health protection to veterinarians working in farm animal practice or in the preparation, processing and distribution of foods of animal origin. Therefore they should have the first and last word on issues around public health protection and food safety. Veterinarians cannot play this important social role without appropriate veterinary education. It has therefore now become obvious, and at the same time necessary for the improvement of veterinary education, that there must be changes in order to better prepare future farm animal veterinarians and public health veterinarians. It is encouraging as well as appreciating that the application of these changes in under- and post-graduate studies has already started in several veterinary medical schools.

It is now agreed that health problems are complex and delivery of appropriate health services depends upon the dynamic efforts of all health professionals. To provide a framework for analyzing the significance of health professionals' activities as related to human health, the significant human health goals identified are. i) Food protection/safety: to protect from food-borne illnesses by detection and appropriate control of foods of animals origin due to physical, chemical or biological agents. ii) Zoonoses prevention: to protect people from diseases transmitted between animals and people through prevention, control and eradication, including profiling force of monitoring and surveillance in animals and humans. iii) Health education: to protect and promote human health through awareness development, teaching health education and consulta-

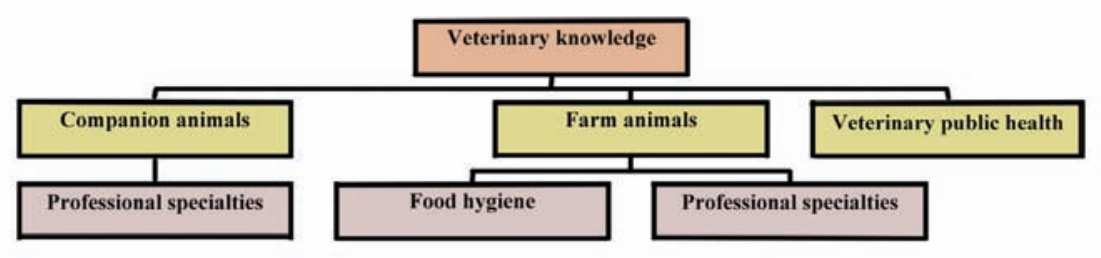

Figure 1. Veterinary knowledge and its major fields.

tion to animal owners, industry groups, and interested individuals.

So it is important to note that the goals as mentioned above are stated in terms of protecting and promoting human health, since these efforts are directed primarily towards preventing the occurrence of disease and dysfunction of people. In Australia consultant veterinarians act to face the situation of food safety. FAO/WHO collaborating center was established in Germany to deal with matters of Food hygiene and zoonoses. In Europe veterinarians act as third party auditor in food safety and HACCP analysis. Many Asian academic institutions have made liaison activities with developed countries for the mutual benefit in the delivery of public health education and continuing professional development. The veterinary faculty of BAU is offering MS degree in VPH (veterinary public health) and FH (food hygiene) and producing experts, but unfortunately the recognition of these experts in this field is still very limited.

\section{The stable to table or farm to fork concept is a major part of veterinary education}

Veterinarians can use their veterinary skills, knowledge and resources to protect and improve human health and welfare. It includes a wide variety of professional areas linking the three elements of the health triangle humans, animals and the environment, with all their interactions. The discipline veterinary education has evolved through three stages, i) beginning with the fight against animal diseases, ii) then moving on to include meat inspection and control of zoonoses and iii) now encompassing a much broader health sciences education, with the goal of guaranteeing a safe and wholesome food supply, protecting human wellbeing and conserving the environment. ${ }^{5}$

Veterinary education all over the world is now giving their students with appropriate knowledge for correct implementation of the stable to table concept. Effective aspects of animal population health management and biosecurity issues are now identified and included in the educational program. This is important with regard to systematic records, and regulation for farm animals in meeting future demands for food quality and safety.

The prerequisite for harmonizing veterinary participation in health and hygiene for obtaining quality food and quality life is very much within the frontier of veterinary education adapted to new demands of the society and nation. The key activities of Public health 
Veterinarians in safety of foods of animal origin are diversified. Figure 2 shows these activities adjusted to particular program.

Several universities in Europe have adjusted their veterinary medicine curricula during the past few years. Experts in the veterinary field predicted determinant changes by 2020 that would influence the work of the veterinarian. All of them were in favor of placing food quality and food safety and public health as the highest priorities in future veterinary education. 4,5 It is now strongly felt that veterinary medical schools should increase farm veterinary management education, incorporating into the current curriculum knowledge of herd health management and HACCP systems. The future public health veterinarians should fully understand that if on-farm production procedures are not fully ensured and hygienically certified by him or her, then the final product that will reach the consumer's table cannot be considered absolutely safe for human consumption.

Veterinary education on animal nutrition (especially clinical nutrition), animal welfare, environmental protection, legislation regarding the veterinary profession, the economics of farm operation, and food technology must also be reinvented and harmonized. Only in this way will veterinarians succeed in implementing transparent safety procedures and effective tracing methods to track food products of animal origin from the stable to the table.2,5 Transparency in processes of food production, until recently a concern only to those few implementing veterinary procedures for con- sumer protection, must now include sciencebased farm animal raising. This can be ensured through the official on-farm presence of a well-educated veterinarian, who always informs on issues of animal health and are ethically prepared to control all procedures of animal raising and thus are responsible to properly and fairly certify the farming operation. The correct implementation of a thorough on farm veterinary management program, transparency during an animal's life, and the ability to trace the origin of consumer goods by the veterinarian responsible for animal health or the veterinarian/food inspector will help the production of hygienically certified animal origin food products that are absolutely safe for human consumption.

Veterinarians are generally in charge of the health certification of animals and animal-origin food products for export, as well as of import controls. As the only animal professionals who are present throughout the modern production chain of foodstuffs of animal origin, veterinarians play a central role in quality control, from farm to fork, from stable to table or from the field to the plate. Moreover, the globalization of animal health issues means that the veterinary profession must develop much closer co-operation with stakeholders, including consumers, commercial partners, the veterinary services in other countries, and supervisory inter-governmental organizations. ${ }^{3,4}$ Veterinary education should underscore the importance of these missions, as well as an extremely high standard of Public Veterinary Services, ${ }^{2-4}$ particularly in such

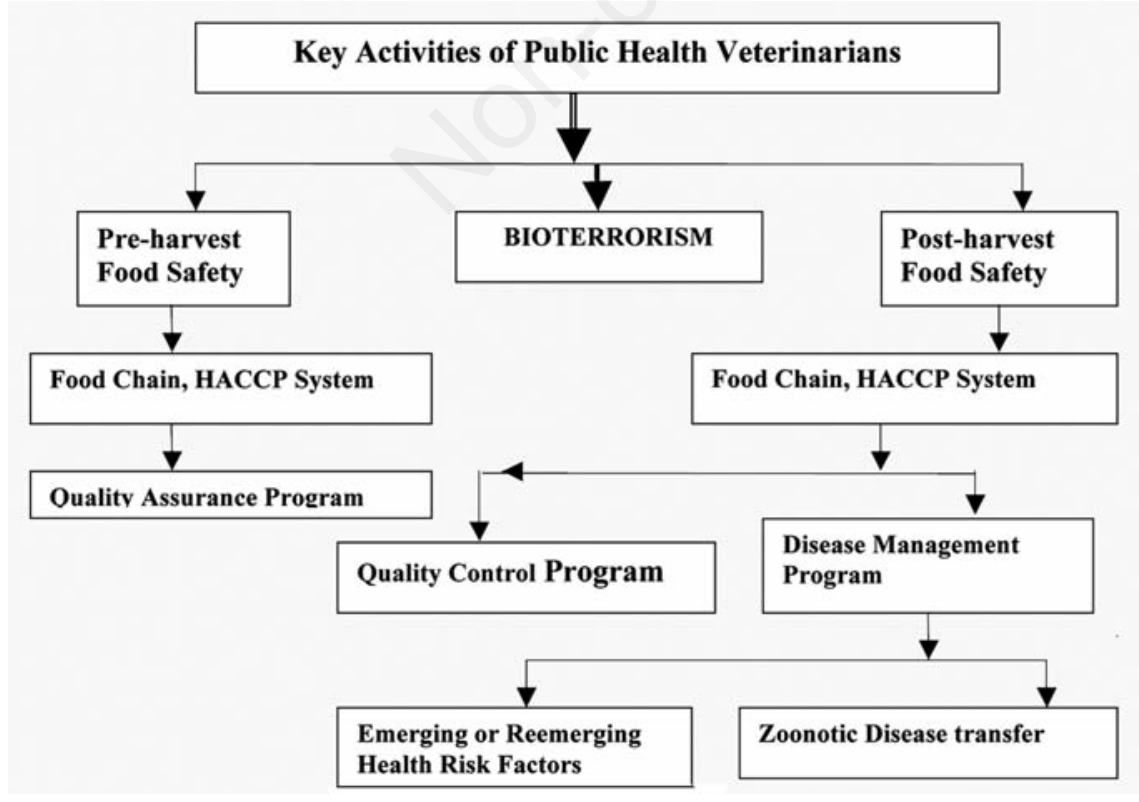

Figure 2. Key activities of public health veterinarians. areas as: i) improved animal health, leading to increase in the quality and quantity of animal protein production and decrease in poverty and malnutrition; ii) public health, including prevention and control of zoonoses transmitted by animals and foods; iii) international veterinary certification, for better access to regional and world markets (including for certain populations of nomadic livestock keepers); iv) the prevention and control of any potential use of animal pathogens in bioterrorism; v) the protection of animals, biodiversity and the environment

\section{Scenario of veterinary education on food safety in Bangladesh}

In Bangladesh only two decades ago veterinary public health was virtually limited to knowledge about foods of animal origin. Zoonoses were little discussed in the infectious disease program but almost no references or connections were made to public health. Students worked in a slaughterhouse only during study tour program. There was little or no emphasis on recognizing pathological changes in carcasses and microbiological implications and the consequences of these findings for food safety. Previously most veterinary curricula were primarily discipline-based, covering the basic traditional pre-clinical, para-clinical and clinical subjects, and produced a generalist veterinarian. ${ }^{6}$

In Bangladesh just after obtaining DVM degree when a young veterinarian is posted at grassroots level, he shoulders the responsibility of giving treatment against the livestock diseases and looks after morbidity and mortality of animal resources of the area under his jurisdiction. Thus his activities are precise to keep vigilance on economics that threaten animal health and animal resources. His pivotal duties are devoted to extension work to create public awareness about measures of prevention and control of diseases of animals and their relation to human health. Time has changed. At the present time the curricula are strengthened. The knowledge now the students acquire in Microbiology, Pathology and Parasitology, Population medicine including Epidemiology and Veterinary public health including Food hygiene are one and almost the same with that of medical profession. His training and academic fitness in Medicine, Surgery and Gynecology will not only give relief to his patients but also give relief to his client from anxiety and economic loss. This veterinarian remains responsible for preventing and controlling of zoonotic diseases by his study of Veterinary Public Health like that of medical 
profession. ${ }^{7}$

In Bangladesh Veterinary Public Health courses are integrated in veterinary curriculum. Universities and Veterinary Colleges of this country are producing qualified Veterinary Food Hygienists to deal with matters of health and demands consumers' food protection. ${ }^{3}$ It is therefore the veterinarians to realize that their responsibility for the well being of man and to form an overall view of their profession. It is unfortunate that Bangladesh is still in infancy in this area. The Veterinary Faculty of Bangladesh Agricultural University is although offering advanced courses in Veterinary Public Health and Food Hygiene to obtain MS degree and thus producing experts, but it is sad to say that the recognition of these experts in this field is very limited.

In the recently introduced curriculum, radical changes are brought. Food hygiene and veterinary public health are now taught as two separate subjects, introducing such topics relevant to public health, such as: slaughter hygiene, meat hygiene and judgment of diseases and controls, HACCP analysis, zoonoses in veterinary practice, the global significance of veterinary public health, the public health risks posed by food animals and companion animals. Moreover, the focus of the slaughterhouse internship has changed from food safety to food quality.

The curriculum of veterinary public health and food hygiene particularly all over the world has been recast, fortified with advanced knowledge components and updated, so that the contribution of future pubic health veterinarians and their services to combat challenges of health components in consumer protection are utilized. At present the Curricula are adjusted to keep pace with developments in the increase in scientific knowledge, in the demands for high-quality service from veterinary clients and in the veterinary profession, where specialization in particular species and sectors is becoming more important. ${ }^{4}$ Two separate programs of veterinary education are proposed to offer by many veterinary schools i) veterinary medicine, clinical and preventive and ii) veterinary food safety, hygiene and ecology. Both programs would provide a comprehensive level of training, so that all graduates are competent to practice in any area of veterinary medicine on the one hand and food safety on the other.

In viewpoint of the aforesaid changes in veterinary education, adjustments of curricula in veterinary faculties have now become our prime needs in Bangladesh, because of the changes occurred in food security and safety, together with the control of zoonotic diseases, international animal health, and the spread of high-impact and trans-boundary diseases. The spread of food-borne disease has been made worse by the globalization of the food supply and intensified food production industries in developing countries. It is envisaged that some important new subjects should be incorporated in the core curriculum of the veterinary undergraduate and post-graduate programs in Bangladesh. The need for an international veterinary public health strategy, involving appropriate veterinary education, should be greatly strengthened which includes the globalization of trade and food, the need to contain the development of antimicrobial resistance and environmental degradation etc.

\section{Role of universities and aca- demic institutions in ensuring food safety in Bangladesh}

The reflection that seems to be unique is that universities and academic institutions have clearly defined their roles in ensuring food safety and improving public health. Our graduate and post-graduate students of veterinary public health and food hygiene take a proper selection of courses to fit them for a career in aspects of food protection, zoonoses, and environmental hygiene and research experience. University personnel can devote more time, facilities, and talents to multidisciplinary problems that may not have immediate importance in practical terms, but could be of great value to generate information for food producers, food processors, and food technologists, food microbiologists and consumers. The use and efficiency tests and standards for quality and problems related to public health must be worked out from academic, regulatory and industrial standpoints. The public health service cannot combat alone the complex situation now we are faced, but that the governmental agencies and academic institutions of our country must work together to delineate many of the problems in food safety, hygiene, consumer protection and public health. 8,9

\section{Syllabus theme of education of veterinary public health and food hygiene course}

Veterinary students should understand the importance of their role in preventing and controlling zoonotic diseases. Traditionally about 25 years ago the VPH course was primarily focused on meat and milk inspection, but now it has been expanded to include:7,8 i) Quality assurance of animal-based products to meet consumer expectations; ii) Knowledge of the causes, epidemiology and control of food-borne diseases, zoonotic and emerging and reemerg- ing diseases; iii) Adverse effects of hormone, antibacterial, agricultural and other human activities on health and food quality; iv) animal welfare, human health and the environment pollution

The interventional activities that the veterinarians can play key roles are diagrammatically illustrated in Figure 3.

\section{Objectives of education}

The main objective of education are the following ones: i) to show students how veterinary public health generally impacts on human health and welfare at local, national and global levels; ii) to recognize the role of the veterinarian in public health and food hygiene; iii) to identify zoonotic diseases (parasitic, viral and bacterial) in animals, especially companion animals and pets, and organize measures to ensure public health safety; iv) to define and identify chemical and antimicrobial residues (existing or potential) in animal products and develop programs to eliminate or avoid them; v) to create public awareness of the occupational risks and hazards such as radiation or chemical or biological hazards which are associated with animal health care; vi) to confer on students the ability to evaluate the economic value of preventative health programs with regards to cost effectiveness; vii) to develop public consciousness of the various health hazards in foods of animal origin; viii) to monitor hygienic handling of food and processing of food products; ix) to make Spearhead investigations into outbreaks of food-borne diseases together with foods and agents associated with such outbreaks; $\mathrm{x}$ ) to understand about environmental hygiene and waste disposal; xi) to know the mechanisms of water purification, storage and water distribution system in a community.

\section{Future directions for veteri- nary education on food safety}

It has become obvious, and at the same time necessary for the improvement of veterinary education, that there must be changes in order to better prepare future public health veterinarians. The application of these changes in under- and post-graduate studies has already started in several veterinary medical schools of the globe.

Many universities in Europe have adjusted their veterinary medicine curricula during the past few years. This was prompted by the Vet2020 project, financed by the European Union (EU), which explored the prospective 
market needs for veterinarians by the year 2020 , and the recommendation of the European Association of Establishments for Veterinary Education that the acquisition of basic knowledge of veterinary science should be combined with more advanced training. All these experts placed food quality and food safety and public health as the highest priorities in future veterinary education.., 5

It is well known that in addition to working in inspected establishments, veterinarians are employed as epidemiologists, food hygienist, microbiologists, pathologists, auditors, risk analysts and biosecurity experts. Veterinarians in developed countries are Veterinary public health experts, executive leaders, international liaisons, and program managers. They investigate outbreaks of food-borne illness in collaboration with local health departments and the National Disease Control and Prevention institutions. They take active part to assess Food inspection programs; design new inspection systems and procedures; evaluate agency programs to determine their effectiveness in ensuring the safety of meat, poultry and egg products; create, promote and deliver training and educational programs; and perform other challenging tasks - the ultimate goal is to protect people from food-borne episodes.

Expert teachers in diverse fields and from many veterinary schools provide knowledge to future veterinarians who will be engaged in food animal practice, education, and / or the practice of food inspection, hygiene, and safety. The veterinary education elevates the standards of food hygiene veterinarians and underscores their professional expertise, thereby providing a strong positive image. It also emphasizes the relationship between veterinary food inspection, food safety, and the public health.

Veterinarians traditionally have a vital role in the advancement and maintenance of food

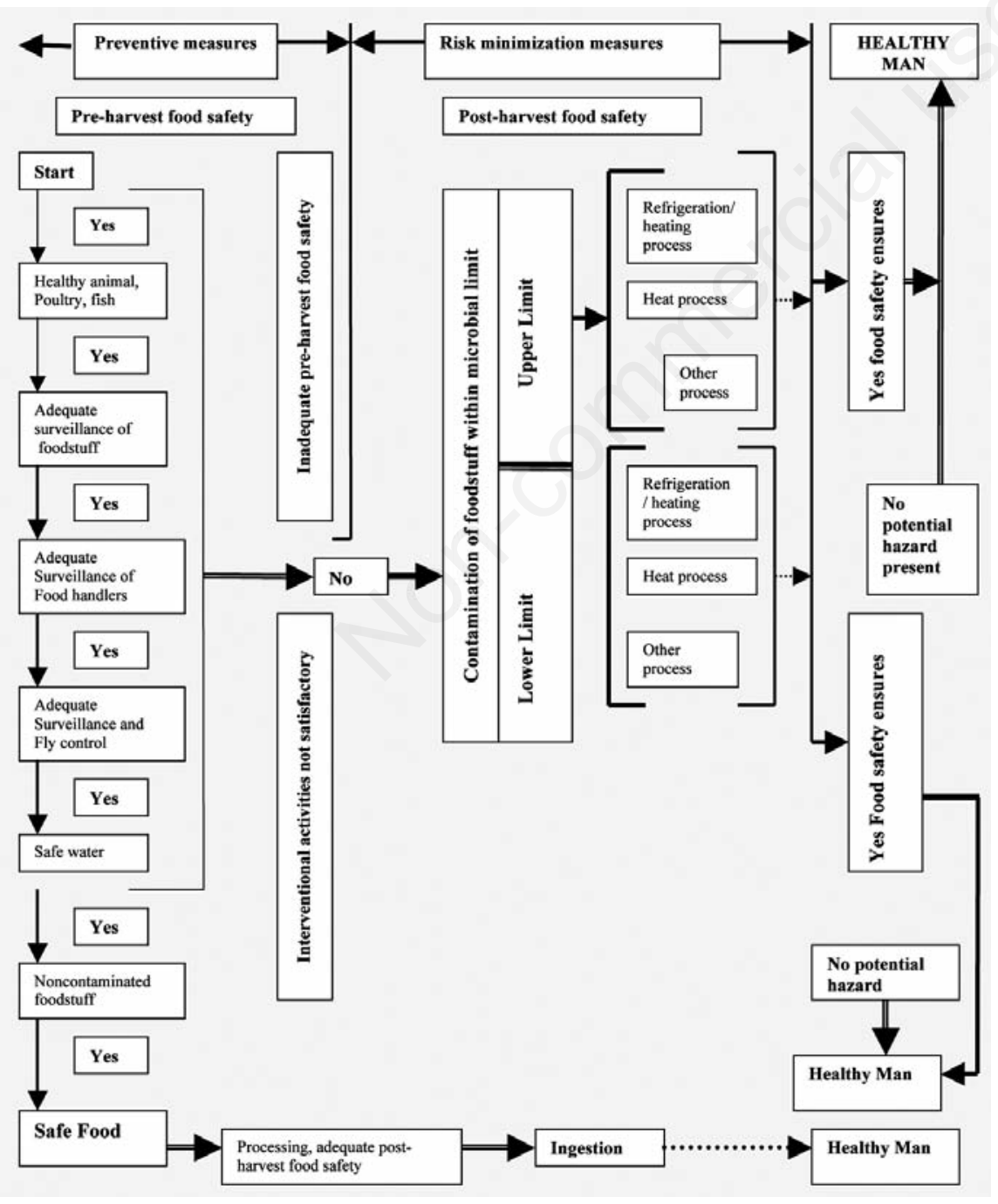

Figure 3. Veterinary Interventional Activities for Food safety and Consumers protection. safety for the benefit of society. There are increasing stresses on our environment and rapid technological changes which can affect the safety of large amounts of food in a short time. Food production and processing technologies are becoming increasingly complex and remote from the consumer. The veterinary profession is the only health profession that is actively involved in all aspects of the food chain from farm production of food animals to the consumption of the food products that derive from those animals. ${ }^{9,10}$

In France, the Ecole Nationale des Services Vétérinaires (ENSV), OIE Collaborating Centre for the Training of Official Veterinarians, hosts future official veterinarians for one or two years. The program includes biological and technical knowledge, such as: i) the prevention and control of transmissible animal diseases; ii) the welfare and protection of animal; iii) technology, microbiology and the management of food safety; iv) animal environments and production.

The main target for the years to come should be to improve the preparation of future farm animal veterinarians in order to better protect public health. The livestock revolution, termed Livestock 2020, will be one of the largest structural shifts to ever affect food markets in developing countries, and will lead to issues of food security, environmental sustainability, food safety, new disease problems, and Public Health. It is very clear that the Livestock 2020 revolution prompts today's veterinary education to shift quickly toward creating the veterinarian of the year 2020 and beyond. 4,5 Farm animal veterinarians and food inspector/veterinarians are the two most important subgroups within the future veterinary profession. They also require a large body of scientific content and specialty knowledge for success. Even to those either now studying or teaching in a veterinary college, it appears that these fields will need to be divided into specialties to better serve the farmer, the consumer, and the economic objectives of a nation. Thus, veterinary students should be properly educated to understand the necessary procedures and the critical control points that require examination to ensure a supply of high-quality, safe products. The elimination of risks to food safety involves the length of the production chain for the final product to reach the consumer's table and still be acceptably safe. In order to achieve the above-mentioned targets, future farm animal veterinarians should be well educated, during their undergraduate studies (from the third up to the tenth or twelfth semester, depending on the school's curriculum), on specific aspects such as the following i) environmental issues related to animal production; ii) animal production and health economics; iii) animal welfare; iv) record keeping at the animal farm level; v) clinical nutrition 
and safeguarding animals' health against pathogens originating from their feed; vi) clinical pharmacology (in order to minimize risks regarding public health, such as drug residues in food products of animal origin, the creation of drug resistant microorganisms, and other problems originating from the current injudicious use of veterinary antibacterial preparations); vii) disease prevention through the application 0 vaccination and metaphylaxis schemes,viii) clinical epidemiology and herd health control; ix) correct implementation of on-farm veterinary management programs, including farm bio-security measures and onfarm HACCP-compatible systems as well as basic principles of good clinical practice (GCP) and good laboratory practice (GLP); $\mathrm{x}$ ) food hygiene and technology (including all the appropriate veterinary interventions needed to ensure transparency throughout all on-farm production procedures and traceability of the final product that reaches the consumer); xi) legislation and specific regulations relevant to veterinary public health, including all food safety issues

The future farm veterinarian should be well educated in the aforementioned topics in order to manage all critical control points when implementing an on-farm HACCP-compatible system. The farm veterinarian, when well educated, should be able to organize, control, and certify the following on-farm procedures: ${ }^{3,4}$ i) appropriate certification of animal feed raw materials (certified either by an agronomist, for products of plant origin, or by a veterinarian, for products of animal origin); ii) the exclusion of most raw materials of animal origin (according to the existing regulations) from animal feeds; high-quality plant-origin feeds should be used instead; iii) regular quality control of long-term stored feeds and drinking water by appropriate laboratory examinations to detect pathogens and toxic compounds; iv) application of an appropriate clinical nutrition program for disease prevention; v) veterinary hygienic certification for incoming and outgoing animals on the farm and strict control of all animals' movements (including proper identification of all animals); vi) complete records for all farm animals, whether kept for breeding or for food production, until 24 months after their removal; computerized records on performance, health, and treatment of every animal on the farm, as well as of all findings at the slaughterhouse, etc.; vii) full application of all welfare rules during raising and transport of animals; viii) correct implementation of appropriate vaccination and metaphylaxis schemes, keeping the use of antibacterial preparations to a minimum and using them only for therapeutic purposes. Use of alternative prophylactic or control substances (probiotics, acidifiers, natural essential oils, etc.); ix) strict adherence to official recommendations for all products used in the farm. Only officially approved products should be used; x) proper implementation of the all invall out animal flow system wherever possible, combined with regular cleaning, disinfection, and control of rodents, insects, and fomites (visitors, vehicles). The effectiveness of these procedures should be continually evaluated, for example, by observing the incidence of common diseases on the farm and by regularly sampling concrete surfaces and measuring bacterial load (housing hygienic measurements); xi) application of essential rules to protect the health of farm workers and medical observation of their health. Human personnel should be subject to frequent health examinations for zoonoses such as leptospirosis, brucellosis, anthrax, and tuberculosis and must be vaccinated against influenza;xii) correct operation of the farm's waste management program and adherence to sanitary and other relevant legislative arrangements for waste disposa; xiii.) complementation of the proper regular sampling protocol at all production stages (both alive and slaughtered animals) to control and prevent specific infectious and parasitic diseases, as well as to minimize the risk of toxic and other health disorders; xiv) appropriate alarm systems and use of back-up emergency systems (e.g., electrical generator) in case of mechanical, electrical, or other malfunctions on the farm; $x v$ ) records of notification of every problem regarding the final products (meat, meat products, milk, eggs, etc.) that reach points of sale and consumers. Frequent control of these products for mycotoxins, chemicals, and potential human pathogens (e.g., Salmonella spp., Campylobacter coli, E. coli 0157, Yersinia spp., Listeria monocytogenes), tracking of the animals responsible, and performing corrective action on farms

The end result of these procedures will deliver hygienically certified food products of animal origin that originate from healthy animals, raised without the use of antibiotics to promote growth.

\section{Food safety policy develop- ment}

Food safety is no doubt a scientific discipline describing handling, preparation, and storage of food in ways that prevent foodborne illness and includes routines that should be followed to avoid potentially severe health hazards. Absence of planned food safety program in Bangladesh leads to food-borne disease that has an enormous public health impact, as well as significant social and economic consequences. According to FAO advisor in Bangladesh high level of gastroenteritis were due to ignorance and unawareness of people and wives and mothers, main cooks of families, who have little knowledge on food safety and hygienic practices.

Alarming increase of adulteration of foodstuffs created a strong public opinion for combating the ferocity of the offence. Mobile courts are now vigilant around the capital and the districts to discover different kinds of food houses, hotels and restaurants which are found to be selling noxious foodstuffs. Electronic media has been giving a wide coverage of various forms of adulteration of foodstuffs consumed by the people at large.

At the present time the government has realized the importance of hygienically produced safe foods whether domestically produced and consumed, imported or exported. The demand of safe and hygienic foods of animal origin (beef, mutton, chicken, ducks, eggs, milk and milk products) is increasing. In Bangladesh the slow progress and the prevailing poor development of national food safety policies and infrastructures have made the establishment for implementing food safety activities to remain in darkness. As a result food standards and codes of hygienic practice; inspection services and laboratory analysis; and promotion of Hazard Analysis Critical Control Point (HACCP) system as a tool for food safety management are not at all practiced.

It is therefore the policy of the government of every country to help assure that the supply of foods of animal origin, including meat, poultry, fish, dairy products and eggs shall be safe and wholesome. The veterinary education is equipped in such a way that the veterinarians after obtaining qualification degree can shoulder responsibility to assist in all matters related to increasing the assessment of safety and quality of meat, milk, fish and shell fish, poultry, and related food products. Bangladesh government with rudimentary food hygiene program should take primary initiative in utilizing veterinary food hygienists and public health veterinarians to components of national and international health and food policy programs. Standards for ensuring food safety, wholesomeness and other health risk factors need to be realized. Otherwise the country may lose prospect for trade in livestock and agricultural commodities.

In view of the above overview of the food safety situation in this country the Government should without any more delay realize the importance of veterinary education and thereby actively pursue appropriate educational, legislative, and regulatory measures to meet the required goals as laid below.

\section{Veterinarians advocacy}

The Veterinary education blends veterinarians with strong capacity to advocate the assur- 
ance of food quality and safety from farm to fork. These encompass the following approaches: i) the production of safe and wholesome food from healthy animals that are raised in a healthful environment with close professional monitoring to reduce traumatic, infectious, and parasitic diseases and chemical or drug residues; ii) mandatory animal identification is needed to enable tracking of diseased animals through marketing channels to point of harvest and trace back to origins; iii) quality assurance programs should be implemented as cooperative efforts between food animal producers and their veterinarians to meet standards established by government regulators and expected by consumers; iv) preharvest certification to comply with production and health standards for food animals should be accomplished by accredited private veterinarians in addition to regulatory veterinarians; v) care of animals and humane treatment throughout production, marketing, and processing; vi) sanitary harvesting of food animals and sanitary processing of foods in scientifically managed facilities where management for producing safe wholesome food products; vii) hygienic, safe handling and storage of foods by trained food handlers in all processing, transportation, wholesale, retail, and food service activities; viii) giving necessary education and training of professional food handlers and food service managers; ix) dissemination of Consumer education with a view to create awareness of the potential risks of improperly handled foods, and to promote personal and food hygiene practices, including proper sanitation, handling, storage, and preparation of meat, milk, dairy products, poultry, eggs, fish and shellfish, and related products to maintain quality and to prevent recontamination and spoilage; $x$ ) the ongoing assessment and mitigation of the vulnerability of the food production continuum to natural and intentional hazards

\section{Governments advocacy}

Government in collaboration with veterinary food hygienist and public health veterinarian should advocate academic and field covered science-based food safety system as a comprehensive process of pre-harvest and post-harvest food safety, ante- and post-mortem evaluation, which includes detection of physical defects, infectious agents, pharmaceuticals, health hazardous elements and chemical residues in food. The system should include: i) study and research on technological and personnel approaches to improve food safety; ii) careful organoleptic examination and sanitary quality determination to exclude unsafe or unwholesome products; iii) monitoring of application facilities and products at slaughter, production, preparation, processing, distribution, and sales; iv) process management and plant sanitation controls to preclude recontamination; v) use of veterinarians' scientific and public health knowledge and skills in the development, promotion, and management of animal health, the prevention minimization of microbiological and chemical contaminants, assessment of the safety of animal products, and protection of public health; vi) development and strengthening of advanced educational programs in food safety for veterinary medical and graduate students and of continuing education in public health and food hygiene for veterinarians and food inspectors

\section{Cooperative advocacy}

Cooperative governmental and educational action toward food safety quality assurance and control advocacy should introduce the following instructive plan and program: i) a coordinated, integrated, unified food safety regulatory program that is effectively enforced and that cooperates closely with state, divisional, and municipal programs should be framed; ii) if food safety is overseen by any agency, then it should be placed under the Departments of Livestock, Agriculture and Fisheries. A single agency should have the expertise, capability and resources to manage the full scope of the food quality assurance and control program as a continuous process through production, processing, distribution, sales, and consumption, including consumers protection, their rights, privilege and education through the cooperative extension service and other forms of outreach; iii) since veterinarians are educated in comparative medicine, pathology, physiology, toxicology, microbiology, pharmacology, immunology, epidemiology, parasitology, pathology, parasitology and public health, therefore the leadership positions in food safety management should be given to public health veterinarians and this should be held by veterinarians; iv) the safety assurance of animal-derived food products throughout processing, distribution and marketing channels should be properly inspected, managed and certified by government regulatory officials as good manufacturing product; v) requirements regarding imported foods should be so made as to meet the same production and quality standards as domestic products; vi) veterinary education on production, purchase, sell, handling, distribution, storage, preparation, and serving foods for food service establishments and consumers should be so maintained as to ensure their hygiene and safety

\section{National and international images in food safety}

The Bangladesh Veterinary Association
(BVA), Bangladesh Veterinary Council (BVC), Director of Livestock Services (DLS) and other related bodies could play professional roles of public health veterinarians. Time has come for taking immediate coordinated program at the national and international level. Standards for ensuring food safety, wholesomeness of foods, and other health risk factors need to be realized. Otherwise our country may lose prospect for food trade in food and agricultural commodities. The hygienic codes of practice of HACCP, GMP, ISO, and CAC should be made mandatory for meat, poultry, egg and fish and their products. In most of the developed countries, particularly in Australia public health veterinarians are given opportunity to face the situation of food safety. We now find a division of veterinary public health under WHO. Collaborating Centers of FAO/WHO are established in Germany to deal with matters related to food hygiene and zoonoses. Many Asian academic institutions, Chiangmai University in Thailand, few Universities of Malaysia and India have made liaison activities with institutions for the mutual benefit in the delivery of veterinary public health education. In European countries veterinarians act as third party auditor in food safety and HACCP analysis. The government of Bangladesh is working with SAARC for harmonization of standards on food products. SAARC Food Security Reserve Board (SFSRB), at its 9th Meeting held in Islamabad, Pakistan in December 2002, urged the member states to consider harmonizing food laws, regulations, standards, quality control system, and control mechanism to facilitate maintenance of food safety for enhancing food trade. SAARC also organized a workshop in Nepal which adopted some recommendations to establish a Regional epidemiological network among the SAARC countries to combat FB-disease outbreaks.

The 3rd meeting of the National Food Safety Advisory Council (NFSAC) held on 22nd August 2010 at the Ministry of Local Government, Rural Development and Cooperatives (LGRDC), Dhaka made decisions on the formation of a NFSAC Standing Technical Committee (STC) at the national level and Technical Sub Committees (TSC) at different Ministry levels. The FAO Food Safety project will assist in preparing the scope and Terms of Reference of the committees. The names of the members of the committees will be communicated by the Secretary, LGRDC to the NFSAC members for their endorsement. In this respect we sincerely hope that in the near future Bangladesh will come forward with veterinary public health responsibilities incorporated in NFSAC planning and program. The concerned authorities in collaboration with international public health authority like WHO should establish a center for food safety, food quality control, and zoonoses. 


\section{Conclusions}

The role played by the veterinary profession in protecting animal and public health, along with food safety, is unique. The comprehensive nature of a veterinary medical doctoral education rightly prepares veterinarians to work at the forefront of public health. At present, veterinary schools all over the world have introduced required courses in the curriculum which emphasize public health or related topics, such as epidemiology, preventive medicine, zoonoses and food safety. Public health is now correctly seen as an important responsibility of the veterinary profession worldwide.

The future role of the veterinarian globally is major and expanding beyond traditional beliefs regarding veterinary medicine and herd health of farm animals. Protecting public health, the environment, and the health of farm animal workers and stockmen, as well as other critical issues, such as HACCP principles, consumers' protection are parts of the veterinarian's responsibilities. It is obvious that educational requirements and teaching obligations in developed countries veterinary schools are increasing, since future veterinarians will have to shoulder the responsibility for all aspects of animal-origin food production in order to safeguard public health. Only if veterinary students understand the challenges of the future and become well educated on the concept from the stable to the table, they will be able to fulfill the future demands of the veterinary profession in the field of health and hygiene, food safety environment pollution. Qualified veterinary food hygienists and public health veterinarians can play leading as well as professional role in vitalizing and strengthening QC and QA programs of food safety and food hazards, in controlling zoonoses, in incor- porating plans for the social and economic development of the country and undertaking collaborative activities with multi-disciplinary national and international agencies.

Finally, the amount of knowledge needed to successfully control all areas of veterinary intervention appears to support veterinary specialization. Specialization would seem imperative mostly for raising farm animal species and for specific areas of veterinary medicine needed for farm certification and certified consumer goods. It could be acquired only through formal post-graduate education and specialization, taking into account a veterinarian's field experience. Within the EU, colleges of veterinary specialties are increasing and providing certification to those who have excellent knowledge in specific aspects of veterinary medicine and veterinary public health and food hygiene, just as American veterinary medical colleges and FSIS (Food Safety Inspection Service) do.

\section{References}

1. Rahman MM, Rahman MB. Viable food safety to mitigate the growing concernment in Bangladesh. Paper presented at the 5th International Conference on Microbiology of Food, Health and Environment: Problems and Prospects in Developing Countries December 26-28, 2010, University of Dhaka, Bangladesh.

2. Kyriakis SC, Alexopoulos C, Tassis PD, et al. On farm veterinary management: biosecurity measures for the production of high hygienic quality animal origin food products. Proceedings of the 3rd Hellenic Symposium on Food Hygiene and Food Technology. Athens, March 18-19, 2004. pp.175-186.

3. Lipman LJA, Van Knapen F. Integrating the issues of global and public health into the veterinary education curriculum: a European perspective. Rev Sci Tech Off Int Epiz 2009;28:745-52.

4. De Castro P, Zucconi S. Development of European educational strategies: design of veterinarian profiles identified by market needs for the year 2020. Vet Res Commun 2004;28:13-28.

5. VET2020. Suggestions for improving the educational requirements of veterinary education in Europe: report of the VET 2020/EAEVE/FIVE ad hoc working group. VET 2020 analysis of trends of prospects for veterinarian profiles and their impact on veterinary training, 2003. pp 1-9.

6. Samad MA, Ahmed MU. History and scope of veterinary medicine. Bang $\mathrm{J}$ Vet Med 2003;1:1-8.

7. Rahman MM. Veterinary public health and zoonotic disease control in Bangladesh. In: Pal SK, Siddiky NA, eds. Veterinary public health and zoonotic disease control in SAARC countries. Dhaka: SAARC Agriculture Centre; 2011. pp. 1- 62.

8. Rahman MM. Notes on veterinary public health. Mymensingh: Bangladesh Agricultural University; 2010. pp 1-193.

9. Rahman MM, Kabir SML. Developing awareness profiling force and activities linking safety and quality and quality of foods of animal origin in Bangladesh. Sci J Rev 2012;1: 84-104.

10. Rahman MM, Rahman MH. Innovating veterinary public health challenges of Bangladesh to integrate the concept of one world, one health. Sci J Rev 2012;1:111-29. 